\title{
Molecular Docking Studies to Understand the Potential Role of Ginger Compounds (6-Gingeroland 6-Shogaol) on Anti-Angiogenic and Anti-Lymphangiogenic Mechanisms
}

\author{
Santhoshi Rani Nanchari ${ }^{1}$, Shyam Perugu ${ }^{2}$, Vijayalakshmi Venkatesan ${ }^{1}$ \\ ${ }^{1}$ Department of Stem cell Research and Biochemistry, National Institute of Nutrition, India \\ ${ }^{2}$ Department of Biotechnology, National Institute of Technology, Warangal, India \\ Correspondence: Vijayalakshmi Venkatesan, Department of Stem cell Research and Biochemistry, National Institute of \\ Nutrition, India. E-mail: v.venkateshan@gmail.com
}

Received: August 18, 2019 Accepted: October 9, 2019 Online Published: December 3, 2019

doi:10.5539/ijc.v12n1p61

URL: https://doi.org/10.5539/ijc.v12n1p61

\begin{abstract}
Background: 6-Gingerol and 6-Shogaol are novel biologically active phenol compounds isolated from rhizomes of Ginger (Zingiber officinale Roscoe), which has a potential role as anti-inflammatory, anti-oxidant and apoptotic. Till date there are no scientific reports on the functional properties of Ginger against the molecular mechanisms of angiogenesis, lymphangiogenesis, and metastasis. Hence, in the present study we have explored the feasibility of active ginger compounds (6-Gingerol and 6-Shogaol) to validate their molecular mechanisms on angiogenesis and lymphangiogenesis in breast cancer progression through in silico approach.
\end{abstract}

Methodology: Studies have been targeted to find the interactions between selected protein receptors, which play a pivotal role in angiogenesis and lymphangiogenesis and ligands of Ginger compounds (6-Gingerol and 6-Shogaol) by using Accelrys discovery studio 2.5, followed by analysis of data.

Results: Based on the in silico approaches, we found the best interactions between ginger compounds (6-Gingerol and 6-Shogaol) and targeted protein molecules as shown less than $3.10 \mathrm{~A}^{0} \mathrm{H}$-bond distance to indicate higher binding affinity and stronger interactions and high docking scores. We demonstrate docking interactions of 6-Gingerol with the proteins involved in angiogenesis like VEGF-A (3QTK), VEGFR-1 (5ABD), VEGFR-2/VEGF-E COMPLEX (3V6B, Angiopoietin-2 (4JZC), PDGF-B (4QCI), KDR (5EW3) and with the proteins involved in lymphangiogenesis such as VEGF-C(2XIX), VEGF-C in complex with domains of 2 and 3 of VEGFR2 (2X1W), NRP2(4QDS) and Neuropilin-1/VEGF-A complex (4DEQ). Similarly, our data shows that 6-Shogaol also interacts with angiogenic specific proteins, like [VEGF-A (3QTK), VEGFR-1 (5ABD), VEGFR-2/VEGF-E COMPLEX (3V6B), Angiopoietin-2 (4JZC), PDGF-B (4QCI), KDR (5EW3)] and lymphangiogenesis [VEGF-C(2XIX), VEGF-C in complex with domains of 2 and 3 of VEGFR2 (2X1W), NRP2(4QDS) and Neuropilin-1/VEGF-A complex (4DEQ)].

Discussion: In silico approaches suggest a stronger binding affinity between the ginger compounds (6-Gingerol and 6-Shogaol) and selected proteins critical in angiogenesis and lymphangiogenesis. The present study underlines the feasibility of neutraceuticals to target the pathways participating in breast cancer progression through neovascularization. Our results also advocate 6-Gingerol to be more potent inhibitor of lymphangiogenesis assessed by its binding efficacy with VEGF-C and NRP2 (4QDS) as compared against 6-Shogaol.

Keywords: angiogenesis, docking, lymphangiogenesis, protein-ligand interactions, 6-gingerol, 6-shogaol

\section{Introduction}

Cancer is a leading cause of death worldwide. According to the reports from the Indian Council of Medical Research, India is likely to have more than 17.3 lakh newly diagnosed cases and over 8.8 lakh deaths due to cancer by the year 2020 (http://www.dailypioneer.com/nation/over-17-lakh-new-cancer-cases-in-india-by-2020-icmr.html). Breast cancer is the most common cancer in India followed by lung and cervical cancer (Include reference). It is estimated that there were nearly 1.5 lakh new cases of breast cancer in 2016, - which is more than $10 \%$ all new cancer cases in 2016 (https://timesofindia.indiatimes.com/india/Cancer-cases-in-India-likely-to-soar-25-by-2020-ICMR/articleshow/5233463 2.cms). The prevalence of primary as well as secondary breast cancer is also increasing alarmingly in Asia due the delay in diagnosis, unawareness as well as treatment failures. Neovascularisation, which is formation of new blood and 
lymphatic vessels, plays a key role in tumor development and progression (Nishida et al, 2006). Several pathways play a vital role in angiogenesis and among these the vascular endothelial growth factor (VEGF) pathway has diverse activity in cell types like muscle (Bryan et al, 2008), neuronal cells (Jin et al, 2006) and endothelial cells (Lee et al, 2007). VEGF family members play a decisive role in formation of new blood vessels, such as induction of gene expression, regulation of vascular permeability, and promotion of cell migration, proliferation, and survival (Hoeben et al, 2004). These are all induced by the binding of VEGF to VEGF-Rs, and the resulting activation of multiple downstream signaling pathways, including Ras/MAPK, FAK/paxillin, PI3K/AKT, and RhoA/ROCK PLC $\gamma$ (Zachary, 2003, Lee et al, 2007 and Johnson and wilgus, 2014) (Figure 1). The VEGF family consists of several proangiogenic proteins like VEGF-A, VEGF-B, VEGF-C, VEGF-D, VEGF-E, and placental growth factor 1 and 2 (PIGF-1 and PIGF-2) (Gilbert, 2000 and Adair et al, 2010). VEGF-A is known as most potent inducer of blood vessel growth, while VEGF-E is more specific for the pathological process of angiogenesis. Over expression of either VEGF-C or VEGF-D in tumors has been shown to significantly increase tumor-associated lymphatic vessel growth (primarily at the tumor margin) and increase the incidence of lymph node metastasis (lymphangiogenesis) (Feng et al, 2010). Neuropilin-1 (NRP1) is a membrane-bound co-receptor for both VEGF and Semaphorin family members. NRP1 plays a versatile role in angiogenesis, axon guidance, cell survival, migration, and invasion (Li et al, 2014). Neuropilin-2 (NRP2) is a receptor for vascular endothelial growth factor-C (VEGF-C), and a lymphangiogenic factor, which plays a major role in lymph node metastasis of various cancers, including breast cancer (Yasuoka et al, 2009). ANGPTL3 is a member of angiopoietin-like family of secreted factors, which consists of a signal peptide, N-terminal coiled-coil domain and the C-terminal fibrinogen (FBN)-like domain (Camenisch et al, 2002). The FBN-like domain in angiopoietin-like3 protein was shown to bind $\alpha-5 / \beta-3$ integrins, which induces endothelial cell adhesion and migration and also play a role in the regulation of angiogenesis as observed for VEGF-A (Camenisch et al, 2002). The isoforms of platelet-derived growth factor (PDGF) (PDGF $\alpha$ and PDGF $\beta$ ) will bind to the class III receptor tyrosine kinases, leading to the autophosphorylation of receptors at tyrosine residues and inducing the downstream signaling and it upregulates VEGF-A production to increase the angiogenic mechanisms (Laschke et al, 2006; Magnusson PU et al, 2007). Lymph endothelial cells express Prox1, which was shown previously to induce lymphangiogenesis by activating VEGFR3 (Srinivasan et al, 2010) and may function as an oncogene or a tumor suppressor gene in a cancer-specific manner. Another protein SerpinF1 (SERPINF1) or pigment epithelium-derived factor (PEDF) has a multi-functional properties (anti tumorigenic and anti angiogensis). PEDF interferes with VEGF signaling through gamma-secretase activity, leading to the cleavage of VEGF receptor 1 (VEGFR-1) transmembrane domain, thereby inhibiting angiogenesis and endothelial cell migration (Cai et al, 2006). Targeting these proteins might ameliorate the angiogenic/ lymphangiogenic capacity and thus can be exploited for the treatment for breast and other cancers. Role of VEGF signaling mechanism on angiogenesis and lymphangiogenesis. (adopted from RiniBl et al, 2007)

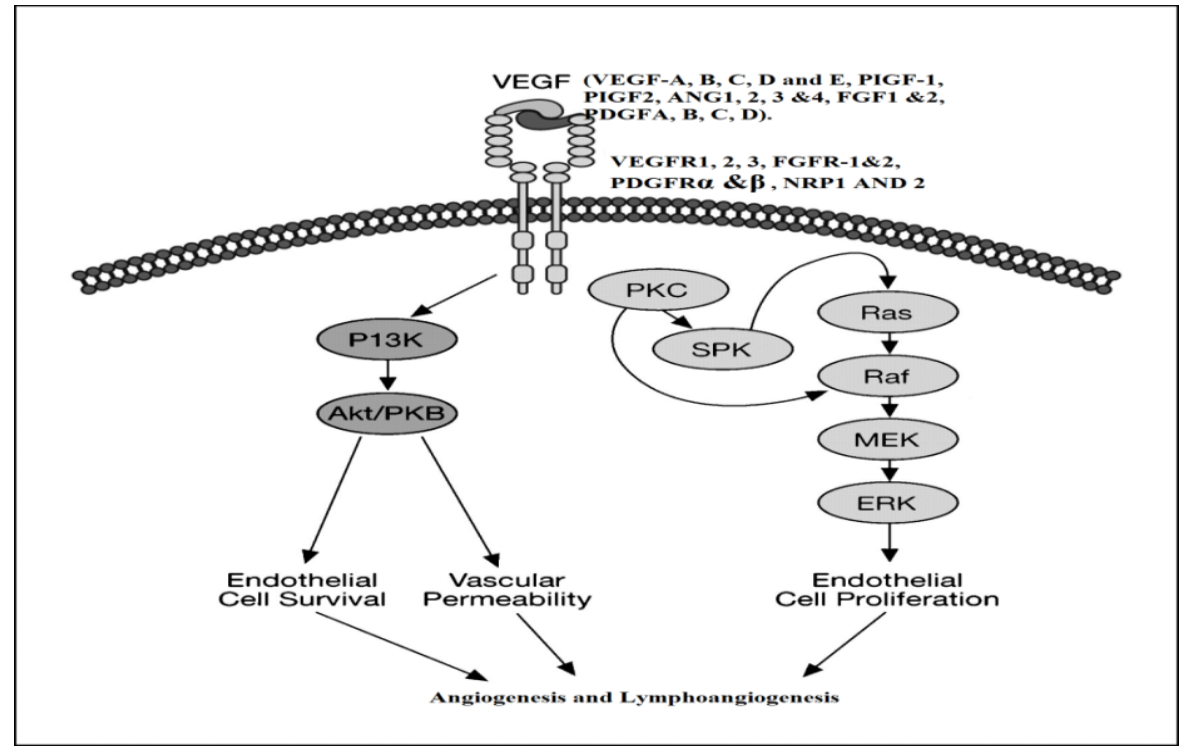

Figure 1. Role of VEGF signaling mechanism on angiogenesis and lymphangiogenesis

Current therapeutic interventions in breast cancer (BC) involves a multimodal approach (chemotherapy, radiation, surgery) based on the clinical heterogeneity. Several angiogenic inhibitors, which are various stages of clinical development, are found to be blocking the neoangiogenesis by depleting nutrients and oxygen to the tumor (Clarke et al, 2006). Till date several drugs have been developed for treatment of cancers such as Bevacizumab, and multikinase 
inhibitors like Sorafenib, Sunitinib and Pazopanibetc(Dey et al, 2015). Inspite of advances made in the diagnosis and treatment modalities, around 20-40\% patients exhibit primary resistance to medical treatment (chemotherapy, hormone therapy, radiotherapy) (Varna et al, 2011) leading to morbidity and mortality. Death rate was found to be higher with cancer because of severe side effects of chemotherapy and radiation therapy.

In recent times, alternate and integrated approach to synergize drugs with neutraceuticals has opened up as a new strategy for better management of cancer. Most noted being naturally available food components like ginger, curcumin, allium vegetables including garlic, which contain the natural anti-Oxidant, anti-inflammatory, anti-cancerous properties (Mashhadi et al, 2013), probably owing to their potent scavenging and apoptotic functions (Nigam et al, 2009). 6-Gingerol and 6-Shogaol are renowned food components isolated from Ginger (ZingiberofficinaleRosc) and well-documented for their contribution to human health and nutrition (Gupta and Sharma, 2014). Indeed the use of Ginger as traditional medicine since immemorial decades as a curative for several diseases, including cancer, diabetes, bronchitis and arthritis... etc (Mashhadi et al, 2013). Several evidences had suggested that Ginger and its active constituents suppress the tumor cell growth, induces apoptosis in a variety of cancers (Radhakrishnan et al, 2014), inhibits vascular endothelial growth factor (VEGF), leads to the cell cycle arrest at G1 phase (Kim et al, 2005) and reduces the inflammatory molecules like Cyclooxgenease (COX2) (Saptarini et al, 2013). In the present manuscript, we hypothesize that Ginger/ its derivatives (6-Gingerol and 6-Shogaol) function as promising nutraceuticals to block both angiogenesis and lymphangiogenesis and metastatic progression.

In the present study we aimed to study how nutraceuticals (Ginger derivatives (6-Gingerol and 6-Shogaol) will arrest the both angiogenesis and lymphangiogenesis progression using molecular docking studies.

\section{Methodology}

In the present study, we aimed to study the molecular docking interactions between ginger compounds (6-Gingerol and 6-Shogaol)(Figure 2a and 2b) and proteins [VEGF-A (3QTK), VEGF-C(2XIX), VEGFR-1 (5ABD), VEGFR-2/VEGF-E COMPLEX (3V6B), VEGF-C in complex with domains of 2 and 3 of VEGFR2 (2X1W), Nrp2 (4QDS), Neuropilin-1/VEGF-A complex (4DEQ), Angiopoietin-1 (4JYO), Angiopoietin-2 (4JZC), PDGF-B (4QCI), SERPINF1(5HGC), KDR (5EW3) and SOX18-HMG/PROX1-DNA (4Y60)], which plays crucial role in angiogenesis and lymph angiogenesis. Molecular docking is used to screening of 6-Gingerol and 6-Shogaol for potential cancer target genes were shown in Figure $3 \mathrm{a}$ and $3 \mathrm{~b}$ and site of interactions were listed in Table 1.

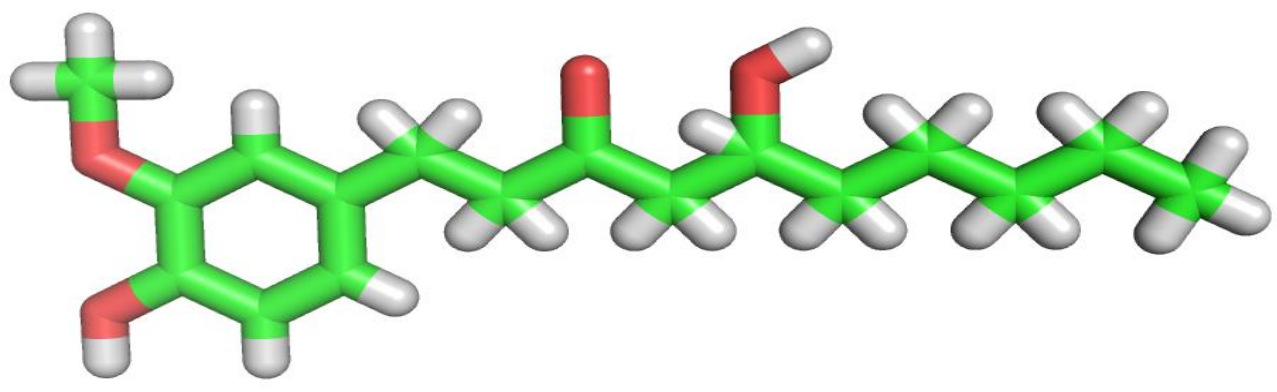

Figure 2a. Structure of 6-Gingerol

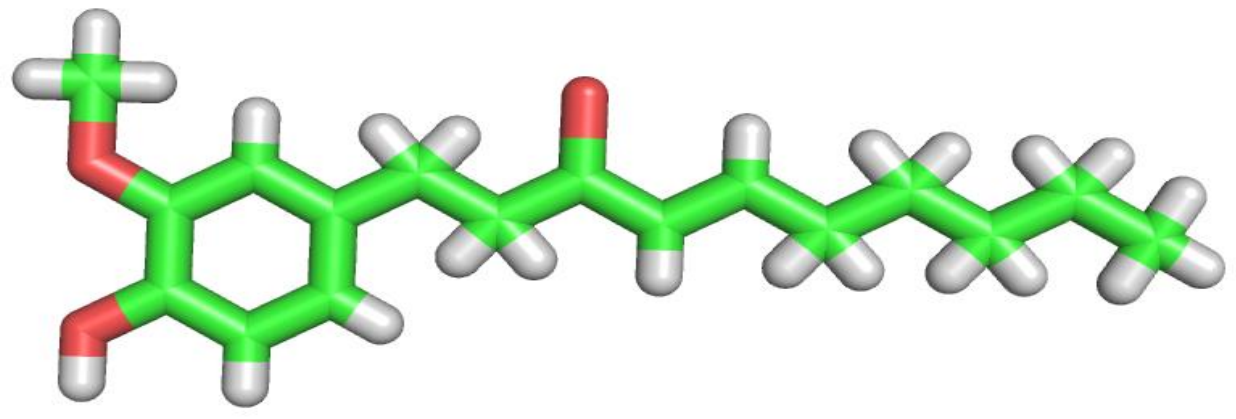

Figure 2b. Structure of 6-Shogaol 


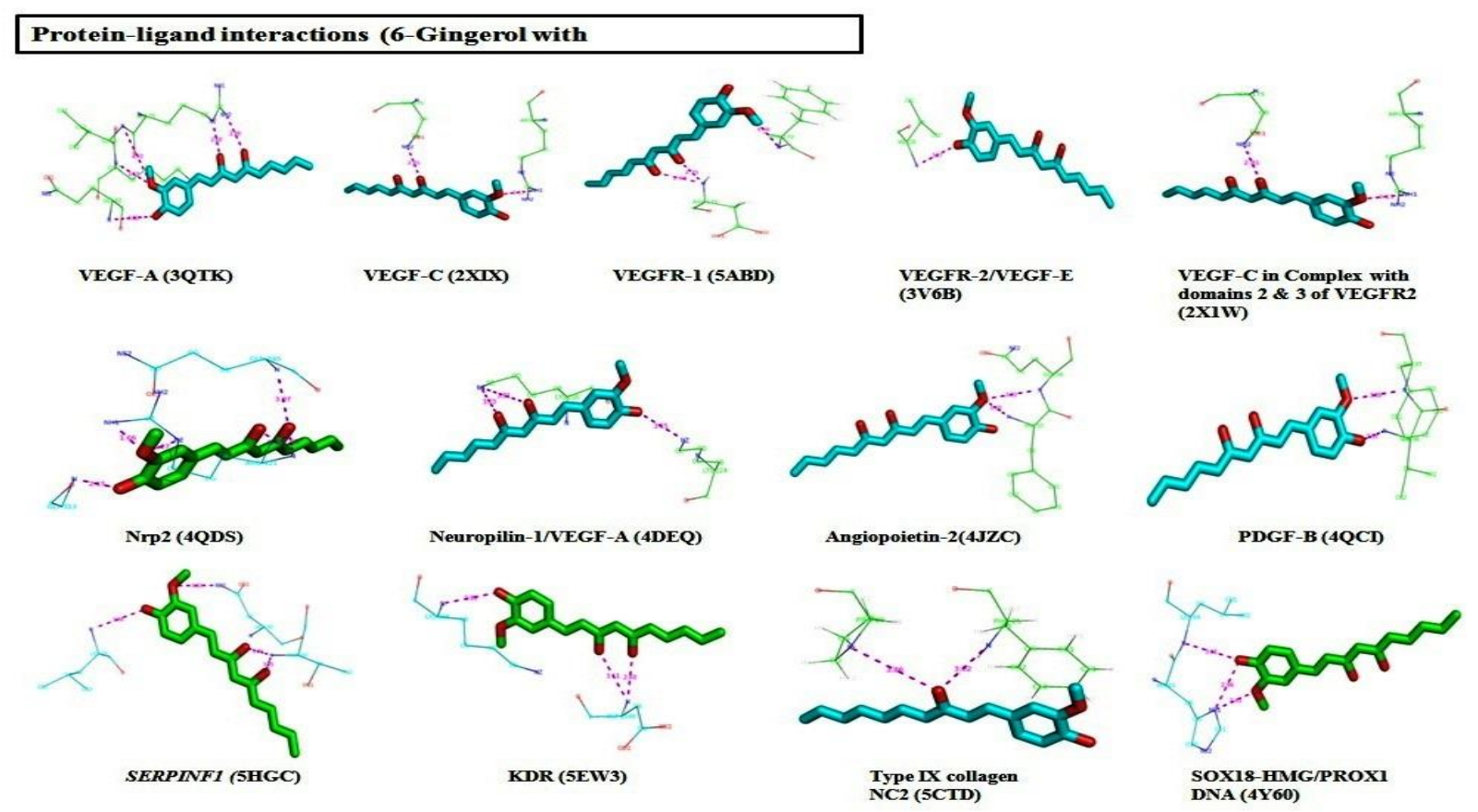

Figure 3a. The docking interactions of the 6-Gingerol with selected proteins involved in angiogenesis and lymphangiogenesis
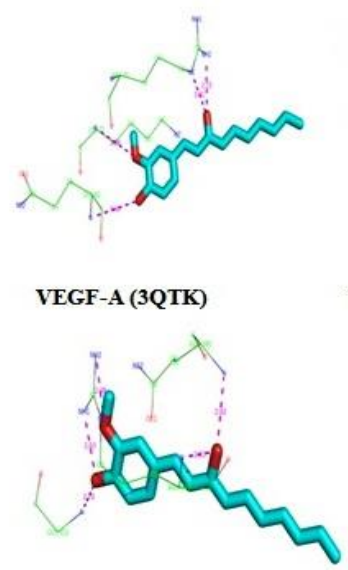

Nrp2 (4QDS)

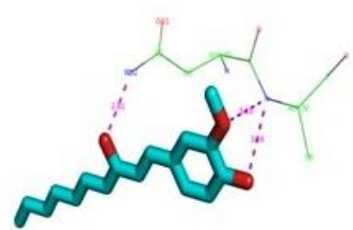

SERPINF1 (5HGC)

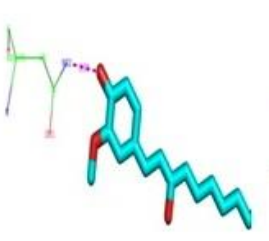

VEGF-C (2XIX)

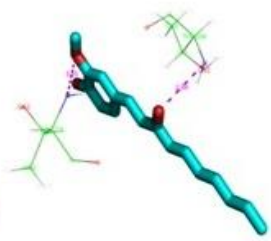

VEGFR-1 (5ABD)

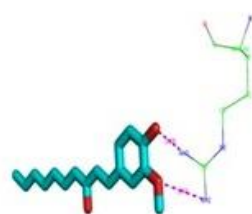

VEGFR-2/VEGF-E (3V6B)

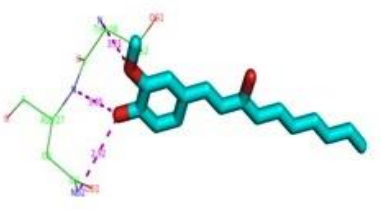

NRP1/VEGF-A (4DEQ)

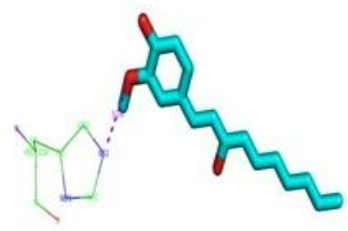

KDR (5EW3)

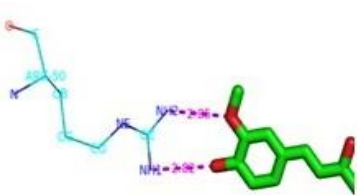

Angiopoietin2(4JZC)

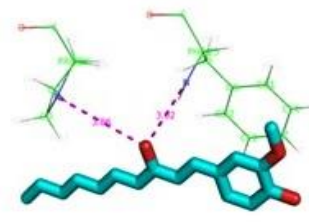

Type IX collagen NC2 (5CTD)

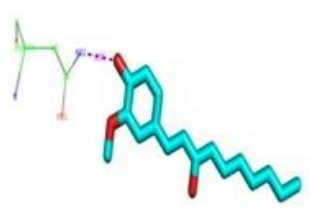

VEGF-C in Complex with domains $2 \& 3$ of VEGFR2 (2X1W)

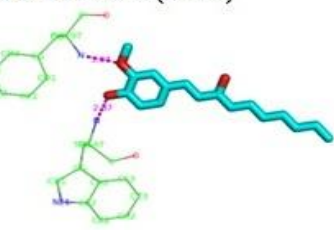

PDGF-B (4QCI)

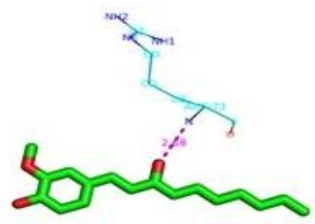

SOX18-HMG/PROX1 DNA (4Y60)

Figure 3b. The docking interactions of the 6-Shogaol with selected proteins involved in angiogenesis and lymphangiogenesis 
Table 1. The docking interactions of the ginger compounds (6-gingero and 6-Shogaol) with selected proteins involved in angiogenesis and lymphangiogenesis

\begin{tabular}{|c|c|c|c|c|}
\hline & & \multicolumn{3}{|c|}{ Interacting Residues } \\
\hline Receptor name & Ligand name & $\begin{array}{l}\text { Ligand } \\
\text { residue }\end{array}$ & $\begin{array}{c}\text { Receptor site } \\
\text { Residue }\end{array}$ & $\begin{array}{c}\text { Distance } \\
\left(\mathbf{A}^{\mathbf{0}}\right)\end{array}$ \\
\hline \multirow[t]{3}{*}{ VEGF-A (3QTK) } & \multirow[t]{2}{*}{ 6-Gingerol } & $\mathrm{O}$ & ARG75-NE & 2.60 \\
\hline & & $\mathrm{O}$ & ARG75-NH2 & 2.89 \\
\hline & 6-Shogaol & $\mathrm{O}$ & ARG75-NH2 & 2.73 \\
\hline \multirow[t]{3}{*}{ VEGF-C (2XIX) } & \multirow[t]{2}{*}{ 6-Gingerol } & $\mathrm{O}$ & ARG161-NH1 & 2.77 \\
\hline & & $\mathrm{O}$ & ARG161-NH1 & 2.80 \\
\hline & 6-Shogaol & $\mathrm{O}$ & ASN175-ND2 & 3.10 \\
\hline \multirow[t]{3}{*}{ VEGFR-1 (5ABD) } & \multirow[t]{2}{*}{ 6-Gingerol } & $\mathrm{O}$ & ASP175-NH & 2.68 \\
\hline & & $\mathrm{O}$ & ASP175-NH & 2.75 \\
\hline & 6-Shogaol & $\mathrm{O}$ & THR166-NH & 2.84 \\
\hline \multirow{2}{*}{$\begin{array}{l}\text { VEGFR-2/VEGF-E } \\
\text { (3V6B) }\end{array}$} & \multirow[t]{2}{*}{ 6-Shogaol } & $\mathrm{O}$ & ARG46-NH1 & 2.71 \\
\hline & & $\mathrm{O}$ & GLY196-NH & 2.79 \\
\hline \multirow{2}{*}{$\begin{array}{l}\text { VEGF-C in Complex with } \\
\text { domains } 2 \& 3 \text { of } \\
\text { VEGFR2 } 2 \text { X1W) }\end{array}$} & 6-Gingerol & $\mathrm{O}$ & ASN175-ND & 2.81 \\
\hline & 6-Shogaol & $\mathrm{O}$ & ASN175-ND2 & 2.59 \\
\hline \multirow[t]{10}{*}{ Nrp2 (4QDS) } & \multirow[t]{5}{*}{ 6-Gingerol } & $\mathrm{O}$ & ARG421-NE & 1.27 \\
\hline & & $\mathrm{O}$ & ARG421-NH1 & 1.66 \\
\hline & & $\mathrm{O}$ & ARG421-NH & 2.12 \\
\hline & & $\mathrm{O}$ & ARG421-NH & 2.89 \\
\hline & & $\mathrm{O}$ & GLY313-NH & 2.15 \\
\hline & \multirow[t]{5}{*}{ 6-Shogaol } & $\mathrm{O}$ & ARG421-NH & 2.13 \\
\hline & & $\mathrm{O}$ & ARG421-NH2 & 2.48 \\
\hline & & $\mathrm{O}$ & ARG421-NH1 & 2.63 \\
\hline & & $\mathrm{O}$ & GLY313-NH & 2.70 \\
\hline & & $\mathrm{O}$ & GLN345-NH & 2.82 \\
\hline \multirow{3}{*}{$\begin{array}{l}\text { Neuropilin-1/VEGF-A complex } \\
\text { (4DEQ) }\end{array}$} & \multirow[t]{3}{*}{ 6-Shogaol } & $\mathrm{O}$ & ASN27-ND2 & 2.92 \\
\hline & & $\mathrm{O}$ & THR26-NH & 3.01 \\
\hline & & $\mathrm{O}$ & THR26-NH & 3.05 \\
\hline \multirow[t]{3}{*}{ Angiopoietin-2(4JZC) } & 6-Gingerol & $\mathrm{O}$ & PHE57-NH & 3.00 \\
\hline & \multirow[t]{2}{*}{ 6-Shogaol } & $\mathrm{O}$ & ARG50-NH1 & 2.82 \\
\hline & & $\mathrm{O}$ & ARG50-NH2 & 2.85 \\
\hline \multirow{4}{*}{$\begin{array}{l}\text { PDGF-B } \\
(4 Q C I)\end{array}$} & \multirow[t]{2}{*}{ 6-Gingerol } & $\mathrm{O}$ & VAL96-NH & 2.93 \\
\hline & & $\mathrm{O}$ & PHE97-NH & 3.08 \\
\hline & \multirow[t]{2}{*}{ 6-Shogaol } & $\mathrm{O}$ & TRP47-NH & 2.87 \\
\hline & & $\mathrm{O}$ & PHE97-NH & 2.04 \\
\hline \multirow[t]{2}{*}{ SERPINF1 (5HGC) } & 6-Gingerol & $\mathrm{O}$ & THR387-NH & 3.05 \\
\hline & 6-Shogaol & $\mathrm{O}$ & ASN135-ND2 & 2.61 \\
\hline \multirow[t]{2}{*}{ KDR (5EW3) } & \multirow[t]{2}{*}{ 6-Gingerol } & $\mathrm{O}$ & LYS868-NH & 2.89 \\
\hline & & $\mathrm{O}$ & ASP1046-NH & 2.60 \\
\hline \multirow[t]{2}{*}{ Type IX collagen NC2 (5CTD) } & 6-Gingerol & $\mathrm{O}$ & PHE25-NH & 3.03 \\
\hline & 6-Shogaol & $\mathrm{O}$ & PHE25-NH & 3.02 \\
\hline \multirow{3}{*}{$\begin{array}{l}\text { SOX18-HMG/ } \\
\text { PROX1-DNA (4Y60) }\end{array}$} & 6-Gingerol & $\mathrm{O}$ & HIS63-ND1 & 2.81 \\
\hline & & $\mathrm{O}$ & HIS63-ND1 & 2.96 \\
\hline & 6-Shogaol & $\mathrm{O}$ & ARG73-NH & 2.68 \\
\hline
\end{tabular}




\section{Molecular Docking Target Preparation}

The target proteins associated with angiogenesis and lymphangiogenesis were downloaded from Protein Data Bank (PDB) (http://www.rcsb.org/pdb/home/home.do) and are listed in (Table 1). For crystal structure of each target, the crystallographic water molecules were removed, the missing hydrogen atoms were added and the energy level of all the targets was minimized using Accelrys Discovery Studio (Dassault Systèmes BIOVIA, BIOVIA Workbook, Release 2017; BIOVIA Pipeline Pilot, Release 2017, San Diego: Dassault Systèmes).The complex protein- ligand docking interactions were performed by Accelrys Discovery Studio (version 2.5) which was used to design the molecules, and protein binding affinities, and number of bonds formed by ligand (6-Gingerol and 6-Shogaol) with the target protein. The molecular docking was performed between the ginger compounds (6-Gingerol and 6-Shogaol) (Figure 2a and 2b) and the protein molecules which are involved in angiogenesis and lymphangiogenesis using Ligfit. Ligfit is a high-throughput algorithm for docking ligands into an active binding site on the receptor, which is also a site-features docking algorithm. Accelrys CHARMm force field was used throughout the simulation before running Ligfit. The bond distance between ligand residues and protein receptor i.e. $<3.10 \mathrm{~A}^{\circ}$ consider to be significant, which has stronger interactions and binding affinity to be high. $>3.10 \mathrm{~A}^{\mathrm{o}}$ was ignored from the docking studies (Table 1 ).

\section{Results and Discussion}

Angiogenesis helps in the supply of nutrients and oxygen through neovascularization of lymph and blood vessels for the tumor establishment and growth (Paduch, 2016). Recent studies had demonstrated that lymphangiogenesis also contributes to the development of metastasis (Christiansen and Detmar, 2011). Vascular endothelial growth factors (VEGF family) are proangiogenic, and plays significant role in angiogenesis and lymphangiogenesis. Several studies had demonstrated that the phenolic compounds of ginger i.e. 6-Gingerol and 6-Shogaol are hydrophobic due to their aromatic ring and methoxy group, and possesses apoptotic, anti inflammatory, anti-metastatic properties. The ligands of ginger compounds (6-Gingerol and 6-Shogaol) have $\mathrm{OH}$ groups on their benzyl ring, which mostly interacts with NH group of selected protein targets such as VEGF-A (3QTK), VEGF-C(2XIX), VEGFR-1 (5ABD), VEGFR-2/VEGF-E COMPLEX (3V6B), VEGF-C in complex with domains of 2 and 3 of VEGFR2 (2X1W), Nrp2 (4QDS), Neuropilin-1/VEGF-A complex (4DEQ), Angiopoietin-2 (4JZC), PDGF-B (4QCI), SERPINF1(5HGC), KDR (5EW3) and SOX18-HMG/PROX1-DNA (4Y60) demonstrating less distance between receptor and ligand cavity $\left(\mathrm{A}^{\mathrm{O}}\right.$ ), and with higher binding affinity, in addition to hydrogen bond interactions or Vander waals force being more in these groups. Oxygen $(\mathrm{O})$ ligand residue of 6-Gingerol had lesser bond interactions and stronger binding affinity with the VEGF family members i.e. the receptor sites of VEGF-A (3QTK) -[ARG75-NE(2.60) and ARG75-NH2(2.89)], VEGF-C (2XIX)-[ARG161-NH1 (2.77) and ARG161-NH1 (2.80)], VEGFR1 (5ABD)-[ASP175-NH (2.68), ASP175-NH (2.75)], VEGFR-2/VEGF-E complex (3V6B)- [ARG46-NH1 (2.90)], VEGF-C in complex with domains 2 and 3 of VEGFR2(2X1W)-[ASN175-ND2 (2.81)] (Table 1) (Figure 3a and 3b). This advocate that 6-Gingerol inhibits the VEGF family members alters vascularization. In vitro and in vivo studies have also confirmed the role of 6-Gingerol to inhibit VEGF, reduce angiogenesis (Kim et al, 2005), whereas oxygen $(\mathrm{O})$ residue of 6-Shogaol also interacts with receptor sites of VEGF-A (3QTK) -[ARG75-NH2 (2.73)], VEGF-C (2XIX)-[ ASN175-ND2(3.10)], VEGFR1 (5ABD)- [THR166-NH (2.84)], VEGFR-2/VEGF-E complex(3V6B)-[ARG46-NH1(2.71) and GLY196-NH (2.79)], VEGF-C in complex with domains 2 and 3 of VEGFR2(2X1W) -[ASN175-ND2 (2.59)] (Table 1) indicating that 6-Shogaol association is significant with VEGF family members and its impact on anti-angiogenic potential. Moreover, oxygen $(\mathrm{O})$ ligand residue of 6-Gingerol is more likely to interact with Nrp2 protein at different receptor sites at ARG421-NE (1.27), ARG421-NH1 (1.66), ARG421-NH (2.12), ARG421-NH (2.89) and GLY313-NH (2.15) and 6-Shogaol with oxygen (O) ligand residue also interacts with NRP2 at receptor site ARG421-NH (2.13), ARG421-NH2 (2.48), ARG421-NH1 (2.63) and GLY313-NH (2.70) with less bond distance and more binding affinity and stronger vander waal interactions. Similarly 6-Gingerol and 6-Shogaol have shown to interact with different receptor sites/ amino acid residues of Neuropilin-1/VEGF-A complex (4DEQ), Angiopoietin-1 (4JYO), Angiopoietin-2 (4JZC), PDGF-B (4QCI), SERPINF1 (5HGC), KDR (5EW3), Type IX collagen NC2 (5CTD) and SOX18-HMG/PROX1-DNA (4Y60) to suggest that 6-Gingerol and 6-Shoagaol had anti angiogenic and anti-mechanistic properties. These hydrophobic interactions might change the angiogenic/lymphangiogenic potential of these selected proteins. Among these selected compounds, the 6-Gingerol is more potent inhibitor of lymphangiogenesis which is more specific to binding with VEGF-C and NRP2.

\section{Conclusions}

The present study using in silico approach, suggest beneficial role of ginger compounds (6-Gingerol and 6-Shogaol) as growth inhibitors and modulators of lymphangiogenesis, angiogenesis molecules (VEGF-A, VEGF-C, Nrp2, Agiopoietin-2, PDGF-B, SERPINF1, KDR.etc) which is involved in metastatic progression of breast cancer. Intervention with 6-Gingerol and 6-Shogaol, which prove to be cost effective and without side effects might be helpful in management of breast cancer patients as well as in related epithelial-mediated cancers. The in silico approach might be useful for therapeutic intervention of novel drugs and control of angiogenesis (lymphangiogenesis) after clinical 
trials on cancer patients. Further, validation of these insilico results will be carried out by in vitro and in vivo studies.

\section{Authors Contributions}

SRN contributed in selection of the ligand and protein receptors, in silico analysis, data analysis, interpretation of the results and writing manuscript. PS contributed in in silico analysis, data analysis, and interpretation of the results. VV is the project coordinator and critical revision of the manuscript.

\section{Acknowledgements}

I would like to thank Director of National Institute of Nutrition for extending all the help to carry out this work and, Indian Council of Medical Research for Providing ICMR-Post Doctoral Support Fellowship to support this work. I would also like to thank Dr. Sathish Kumar. Mungamuri for his valuable suggestions for the manuscript.

\section{Conflict of Interest}

Authors do not have a conflict of interest.

\section{References}

Adair, T. H., \& Montani, J. P. (2010). Angiogenesis. San Rafael (CA): Morgan \& Claypool Life Sciences.

Biovia, D. S. (2017). Discovery studio modeling environment.

Bryan, B., Walshe, T., Mitchell, D., Havumaki, J., Saint-Geniez, M., Maharaj, A., ... D'Amore, P. (2008). Coordinated Vascular Endothelial Growth Factor Expression and Signaling During Skeletal Myogenic Differentiation. Molecular Biology of the Cell, 19(3), 994-1006. https://doi.org/10.1091/mbc.e07-09-0856

Cai, J., Jiang, W. G., Grant, M. B., \& Boulton, M. (2006). Pigment epithelium-derived factor inhibits angiogenesis via regulated intracellular proteolysis of vascular endothelial growth factor receptor 1". The Journal of Biological Chemistry, 281 (6), 3604-3613. https://doi.org/10.1074/jbc.M507401200

Camenisch, G., Pisabarro, M. T., Sherman, D., Kowalski, J., Nagel, M., Hass, P., ... Gerber, H. P. (2002). ANGPTL3 Stimulates Endothelial Cell Adhesion and Migration via Integrin av 3 and Induces Blood Vessel Formation in Vivo.The Journal of Biological Chemistry, 277, 17281-17290. https://doi.org/10.1074/jbc.M109768200

Cao, Y., Hoeppner, L. H., Bach, S. E. G. Q., Guo, Y., Wang, E., \& Mukhopadhyay, D. (2013). Neuropilin-2 promotes extravasation and metastasis by interacting with endothelial $\alpha 5$ integrin. Cancer Research, 73(14), 4579-4590. https://doi.org/10.1158/0008-5472.CAN-13-0529

Christiansen, A., \& Detmar, M. (2011). Lymphangiogenesis and Cancer. Genes \& Cancer, 2(12), 1146-1158. https://doi.org/10.1177/1947601911423028

Dey, N., De, P., \& Brian, L. J. (2015). Evading anti-angiogenic therapy: resistance to anti-angiogenic therapy in solid tumors. American Journal of Translational Research, 7(10), 1675-1698. https://doi.org/10.1038/bjc.2014.439

Discovery, S. (2007). version 2.5; Accelrys Inc.: San Diego, CA.

Feng, Y., Wang, W., Hu, J., Ma, J., Zhang, Y., \& Zhang, J. (2010). Expression of VEGF-C and VEGF-D as significant markers for assessment of lymphangiogenesis and lymph node metastasis in non-small cell lung cancer.Anat Rec (Hoboken), 293(5), 802-812. https://doi.org/10.1002/ar.21096

Gilbert, S. F. (2000). Developmental biology (6th Edition). Sunderland (MA): Sinauer Associates.

Gupta, S. K., \& Sharma, A. (2014). Medicinal properties of Zingiberofficinale Roscoe - A Review.IOSR Journal of Pharmacy and Biological Sciences, 9(5), 124-129. https://doi.org/10.9790/3008-0955124129

Hoeben, A., Landuyt, B., Highley, M. S., Wildiers, H., Van Oosterom, A. T., \& De Bruijn, E. A. (2004). Vascular Endothelial Growth Factor and Angiogenesis. Pharmacological Reviews, 56 (4), 549-580.https://doi.org/10.1124/pr.56.4.3

Ji, Y., Lu, X., Zhong, Q., Liu, P., An, Y., Zhang, Y., ... Zheng, Y. (2013). Transcriptional profiling of mouse uterus at pre-, implantation stage under VEGF repression. PLoS One, 8(2), e57287. https://doi.org/10.1371/journal.pone.0057287

Jin, K., Mao, X. O., \& Greenberg, D. A. (2006). Vascular endothelial growth factor stimulates neurite outgrowth from cerebral cortical neurons via Rho kinase signaling. J. Neurobiol., 66(3), 236-242. https://doi.org/10.1002/neu.20215

Johnson, K. E., \& Wilgus, T. A. (2014). Vascular Endothelial Growth Factor and Angiogenesis in the Regulation of Cutaneous Wound Repair. Advances in Wound Care, 3(10), 647-661. https://doi.org/10.1089/wound.2013.0517 
Kim, E. C., Min, J. K., Kim, T. Y., Lee, S. J., Yang, H. O., Han, S., ...Kwon, Y. G. (2005). [6]-Gingerol, a pungent ingredient of ginger, inhibits angiogenesis in vitro and in vivo.BiochemBiophys Res Commun., 335(2), 300-308. https://doi.org/10.1016/j.bbrc.2005.07.076

Laschke, M. W., Elitzsch, A., Vollmar, B., Vajkoczy, P., \& Menger, M. D. (2006). Combined inhibition of vascular endothelial growth factor (VEGF), fibroblast growth factor and platelet-derived growth factor, but not inhibition of VEGF alone, effectively suppresses angiogenesis and vessel maturation in endometriotic lesions. Hum Reprod., 21(1), 262-268. https://doi.org/10.1093/humrep/dei308

Lee, S., Chen, T., Barber, C., Jordan, M., Murdock, J., Desai, S., ... Iruela-Arispe, M. (2007). Autocrine VEGF signaling is required for vascular homeostasis. Cell, 130(4), 691-703. https://doi.org/10.1016/j.cell.2007.06.054

Li, X., Parker, M. W., \& Vander Kooi, C. W. (2014). Control of Cellular Motility by Neuropilin-mediated Physical Interactions. Biomolecular Concepts, 5(2), 157-166. https://doi.org/10.1515/bmc-2013-0035

Magnusson, P. U., Looman, C., Ahgren, A., Wu, Y.,, Claesson-Welsh, L., \& Heuchel, R. L. (2007). Platelet-derived growth factor receptor-beta constitutive activity promotes angiogenesis in vivo and in vitro. ArteriosclerThrombVasc Biol., 27(10), 2142-2149. https://doi.org/10.1161/01.ATV.0000282198.60701.94

Mashhadi, N. S., Ghiasvand, R., Askari, G., Hariri, M., Darvishi, L., \& Mofid, M. R. (2013). Anti-Oxidative and Anti-Inflammatory Effects of Ginger in Health and Physical Activity. Review of Current Evidence. International Journal of Preventive Medicine, 4(1), S36-S42.

Nigam, N., Bhui, K., Prasad, S., George, J., \& Shukla, Y. (2009). [6]-Gingerol induces reactive oxygen species regulated mitochondrial cell death pathway in human epidermoid carcinoma A431 cells. ChemBiollnteract, 14, 181(1), 77-84. https://doi.org/10.1016/j.cbi.2009.05.012

Nishida, N., Yano, H., Nishida, T., Kamura, T., \& Kojiro, M. (2006). Angiogenesis in Cancer. Vascular Health and Risk Management, 2(3), 213-219. https://doi.org/10.2147/vhrm.2006.2.3.213

Paduch, R. (2016). The role of lymphangiogenesis and angiogenesis in tumor metastasis. Cellular oncology (Dordrecht), 39(5), 397-410. https://doi.org/10.1007/s13402-016-0281-9

Radhakrishnan, E., Bava, S. V., Narayanan, S. S., Nath, L. R., Thulasidasan, A. K. T., Soniya, E. V., \& Anto, R. J. (2014). [6]-Gingerol Induces Caspase-Dependent Apoptosis and Prevents PMA-Induced Proliferation in Colon Cancer Cells by Inhibiting MAPK/AP-1 Signaling. PLoS ONE, 9(8), e104401. https://doi.org/10.1371/journal.pone.0104401

Rini, B. L. (2007). Vascular Endothelial Growth Factor, Targeted theraphy in renal cell carcinoma: Current status and Future directions.Clin. Cancer Res., 13(4). https://doi.org/10.1158/1078-0432.CCR-06-1989

Sabine, A., Agalarov, Y., Maby-El, H. H., Jaquet, M., Hagerling, R., Pollmann, C., ... Petrova, T. V. (2012). Mechanotransduction, PROX1, and FOXC2 cooperate to control connexin37 and calcineurin during lymphatic-valve formation. Developmental Cell, 22, 430-445. https://doi.org/10.1016/j.devcel.2011.12.020

Saptarini, N., Sitorus, E., \& Levita, J. (2013). Structure-Based inSilico study of 6-Gingerol, 6-Ghogaol and 6-Paradol, active compounds of Ginger (Zinger officinale) as COX2 Inhibitors. .International Journal of Chemistry, 5(3), P12. https://doi.org/10.5539/ijc.v5n3p12

Srinivasan, R. S., Geng, X., Yang, Y., Wang, Y. D., Mukatira, S., ... Oliver, G. (2010). The nuclear hormone receptor Coup-TFII is required for the initiation and early maintenance of Prox 1 expression in lymphatic endothelial cells. Genes Dev, 24, 696-707. https://doi.org/10.1101/gad.1859310

Varna, M., Bousquet, G., Plassa, L. F., Bertheau, P., \& Janin, A. (2011). TP53 Status and Response to Treatment in Breast Cancers, Journal of Biomedicine and Biotechnology, 9. https://doi.org/10.1155/2011/284584

Yasuoka, H., Kodama, R., Tsujimoto, M., Yoshidome, K., Akamatsu, H., Nakahara, M,... Nakamura, Y. (2009). Neuropilin-2 expression in breast cancer: correlation with lymph node metastasis, poor prognosis, and regulation of CXCR4 expression. BMC Cancer, 7(9), 220. https://doi.org/10.1186/1471-2407-9-220

Zachary, I. (2003). VEGFsignalling: integration and multi-tasking in endothelial cell biology. BiochemSoc Trans, 31(6), 1171-1177. https://doi.org/10.1042/bst0311171

\section{Copyrights}

Copyright for this article is retained by the author(s), with first publication rights granted to the journal.

This is an open-access article distributed under the terms and conditions of the Creative Commons Attribution license (http://creativecommons.org/licenses/by/4.0/). 